\title{
EFFECTS OF ADRENAL DEMEDULLATION AND PERIPHERAL NORADRENALINE-DEPLETING AGENTS ON ADRENOCORTICAL FUNCTION AND SPLEEN IN RATS
}

\author{
Minoru INABA, Kunie KAMATA and Momoko KAMIDE \\ Department of Pharmacology, Kyorin University School of Medicine. \\ Mitaka. Tokyo 181. Japan
}

Accepted June 1, 1981

\begin{abstract}
Adrenocortical functions of adrenal-demedullated rats (ADM $M_{X}$ rats) and peripherally chemical-sympathectomized $A D M_{x}$ rats were studied by examining changes in the levels of serum and adrenal corticosteroids (CS). Resting levels of serum and adrenal CS were not influenced by adrenal-demedullation and peripheral chemical-sympathectomy with 6 hydroxydopamine. Diurnal variation in serum CS concentration was also unchanged, suggesting that peripheral adrenergic systems do not influence the basal function of hypothalamo-pituitary-adrenocortical axis. Exposure of $A D M_{x}$ rats to the stressful stimuli, however, resulted in lowered adrenocortical response with a lesser increase in serum CS concentration. while peripheral chemical-sympathectomy of $A D M_{x}$ rats with 6 -hydroxydopamine or guanethidine caused a significant enhancement of adrenocortical response to the stress with elevation of the serum CS concentrations. These findings suggest that increased peripheral adrenergic activity may suppress the activation of the hypothalamo-pituitary-adrenocortical system as the animals were exposed to the stressful stimuli. Adrenal-demedullation produced no increase in spleen weight while chemical-sympathectomy by peripheral administration of 6 -hydroxydopamine did produce a significant increase in the weight of this organ. Histological features following chemical-sympathectomy are described.
\end{abstract}

Functional participation of the peripheral adrenergic system for regulation of hypothalamo-pituitary-adrenocortical function has been discussed by a few investigators $(1,2)$ in contrast to the extensive research on the regulation mechanisms of adrenocorticotropic hormone (ACTH) secretion by central noradrenergic system (3). Advancement in the development of specific chemical agents which affect preferentially the synthesis, storage, release and uptake of neurotransmitters has provided additional knowledge on the control mechanism of ACTH release. 6-Hydroxydopamine reportedly destroys peripheral adrenergic nerve endings leading to a suppression of peripheral adrenergic function in adult rats (4). Chronic administration of guanethidine to rats also produces similar effects (5). These agents. however, did not decrease the levels of catecholamines in the adrenal medulla. To assess the contribution of the peripheral adrenergic system to regulation of the pituitary-adrenocortical function, we gave these chemical agents to adrenal-demedullated rats $\left(A D M_{x}\right.$ rats). In this paper. we describe the changes in basal levels, diurnal variation of serum and adrenal 
corticosteroids (CS), and response of adrenocortical gland to stressful stimuli on CS elevation by peripheral administration of 6 hydroxydopamine or guanethidine to intact rats as well as $A D M_{x}$ rats. Changes in the weight and histologic features of the spleen are also described.

\section{MATERIALS AND METHODS}

Chemicals: 6-Hydroxydopamine and guanethidine were purchased from Sigma Chemical Company and pentobarbital sodium from Abbott Laboratories. Alumina (Alumina Woelm N. Akt. 1) was purchased from Woelm Pharma, washed with $2 \mathrm{~N}$ hydrochloric acid and water, and activated by heating at $120^{\circ} \mathrm{C}$ for $60 \mathrm{~min}$ and then at $200^{\circ} \mathrm{C}$ for $120 \mathrm{~min}$ (6). Organic solvents of reagent grade were purchased from Wako Pure Chemicals.

Animals: Male Donryu rats weighing $50-$ $100 \mathrm{~g}$ were purchased from Nippon Rat Co. Saitama, Japan. They were fed a laboratory chow diet (CE-2. Nihon Clea Co., Tokyo) and water ad libitum in an airconditioned animal room $\left(23 \pm 1^{\circ} \mathrm{C}\right)$ illuminatated from 6:00 to 18:00 o'clock. These rats were handled when weighed daily between 9:0010:00 a.m.

Adrenal-demedullation: When these rats weighed $150-200 \mathrm{~g}$, the adrenal medullae were enucleated under pentobarbital anesthesia $(50 \mathrm{mg} / \mathrm{kg}$ body weight, i.p.). These so-prepared rats were kept on saline instead of water for one week, in the separate cages. Then 5 adrenal-demedullated rats (ADMr rats) of the same litter were put together in one cage and fed laboratory chow and water for one week. Complete abscence of adrenal medulla in ADM $x$ rat was confirmed by histologic examination of the adrenal gland (Fig. 1).

Chemical sympathectomy: $A D M_{x}$ rats or intact rats were subjected to a peripheral chemical-sympathectomy by giving 6hydroxydopamine into the tail vein 4 times

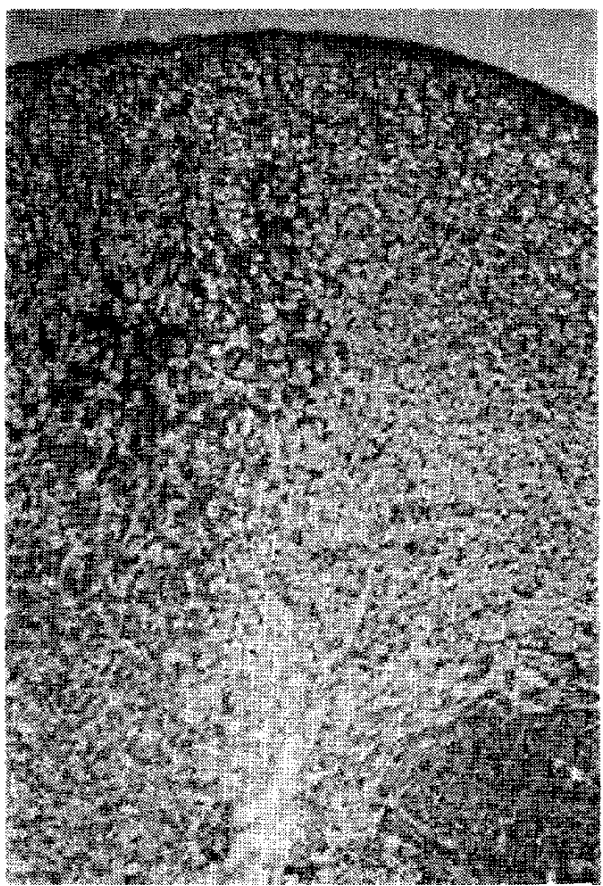

Fig. 1. Defective medullary tissue in a medullectomized rat adronal gland. Evidence of the regenerated adrenocortical tissue without a medulla 2 weeks after enucleation. Procedure of adrenal demedullation is described in the toxt. H-E stain $\times 50$.

in 2 weeks according to Angeletti (4) Control rats were given saline instead of 6-hydroxydopamine. Guanethidine was also used for peripheral chemical-sympathectomy by chronic i.p. administration according to Johnson and O'Brien (5). Decrease in abrupt elevation of the levels of blood catecholamines after decapitation was valid proof for adrenal demedullation and peripheral chemical-sympathectomy (Fig. 2).

Determination of serum and adrenal corticosteroids: One week after chemicalsympathectomy, rats were decapitated instantaneously at a definite time between 10:00 and 10:30 a.m. with a guiliotinetype cutter. In an experiment to examinine diurnal variation of blood CS concentration. the animals were killed between 10:00 and 10:30 a.m. and between 4:00 and 4:30 p.m. 


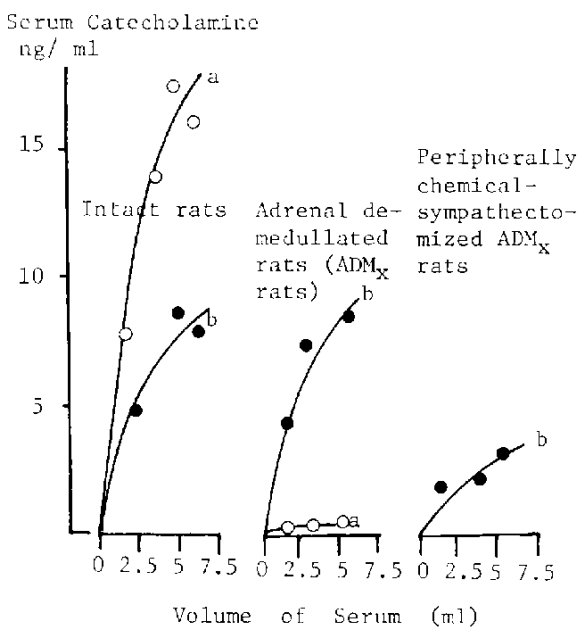

Fig. 2. Time-course of increases in adrenaline and noradrenaline concentrations in blood collected immediately after decapitation of rats. Trunk blood was collected in 3-4 conical centrifuge tubes continuously from the decapitated rat. Procedure for determination of adrenaline and noradrenaline is described in the text. a: Adrenaline. b: Noradrenaline.

Trunk blood was collected in the conical centrifuge tubes in ice-cold water and the adrenal glands quickly removed. Serum and adrenal CS were determined fluorometrically by a modified method (7) of Guillemin et al. (8). Corticosterone was used as reference steroid.

Determination of serum catecholamines: To $0.5 \mathrm{ml}$ aliquots of serum was added $2 \mathrm{ml}$ of $0.4 \mathrm{~N}$ perchloric acid and the preparation was centrifuged at $10,000 \times \mathrm{g}$ for $20 \mathrm{~min}$ at $0^{\circ} \mathrm{C}$. To $1.5 \mathrm{ml}$ aliquots of the supernatant was added $2 \mathrm{ml}$ of EDTA solution containing $200 \mathrm{mg}$, the $\mathrm{pH}$ adjusted to 5-6 with diluted ammonia solution, and finally $100 \mathrm{mg}$ of activated alumina was added. Catecholamines in the reagent mixture were absorbed to alumina by constant shaking of the mixture for $15 \mathrm{~min}$ at room temperature, eluted with acidic methanol from alumina, and separated into adrenaline and noradrenaline using Shimadzu's LC-1 type of high-speed liquid chromatograph. Adrenaline and noradrenaline were determined fluorometrically by the THI method. One ng each of the reference adrenaline and noradrenaline was run simultaneously before and after the samples.

Exposure to stressful stimuli: Rats were exposed to cold environment $\left(4-6^{\circ} \mathrm{C}\right)$ for $30 \mathrm{~min}$ (cold stress). Forcing the rats to move a distance of about $50 \mathrm{~m}$ on a carrier (transfer stress) or forced-swimming for $5 \mathrm{~min}$ in $25^{\circ} \mathrm{C}$-water (forced-swimming stress) was also used in other experiments. Rats were killed immediately after being exposed to such stress.

Examination of spleen: Soon after decapitation, the spleen was removed, cleaned, weighed and fixed in 10\% formalin. Sections of tissue were stained with hematoxylin-eosin for histologic examination.

\section{RESULTS}

Resting levels of adrenal and serum CS in $\mathrm{ADM}_{\mathrm{X}}$ and chemically-sympathectomized $A D M_{X}$ rats: Resting levels of adrenal and serum CS of $\operatorname{ADM}_{x}$ and chemicallysympathectomized $A D M_{x}$ rats at the period of time between 10:00 and 10:30 a.m. were not significantly different from that of the control intact rats (Table 1). Resting levels of serum CS at the period between 4:00 and 4:30 p.m. of $A D M_{X}$ and chemicallysympathectomized $A D M_{x}$ rats were not significantly different from that of the control intact rats. The levels in the afternoon were significantly higher than those in the morning in the 3 groups of rats (Fig. 3 ). Thus diurnal variation of serum CS concentration was not affected either by adrenal demedullation or by peripheral chemical-sympathectomy.

Changes in the levels of serum CS of $A D M_{x}$ and chemically-sympathectomized $A D M_{X}$ rats in the stressful conditions: When $A D M_{x}$ rats were exposed to stressful stmuli such as transfer-, cold-, and forced-swimming stress, significant increase in serum CS was evident, but the extent of this increase was 
Table 1. Resting levels of adrenal and serum corticosteroids in the intact, adrenal demedullated, and peripherally chemical-sympathectomized adrenal demedullated rats

\begin{tabular}{|c|c|c|c|}
\hline \multirow{2}{*}{ Rats } & \multirow{2}{*}{$N$} & \multicolumn{2}{|c|}{ Corticosterone } \\
\hline & & $\begin{array}{c}\text { Adrenal } \\
(\mu \mathrm{g} / 100 \mathrm{mg})\end{array}$ & $\begin{array}{c}\text { Serum } \\
(\mu \mathrm{g} / 100 \mathrm{ml})\end{array}$ \\
\hline Intact & 18 & $2.3 \pm 1.6$ & $4.2 \pm 2.2$ \\
\hline Adrenal demedullated & 16 & $2.9 \pm 1.7$ & $6.5 \pm 4.8$ \\
\hline $\begin{array}{l}\text { Peripherally chemical- } \\
\text { sympathectomized adrenal } \\
\text { demedullated }\end{array}$ & 20 & $3.5 \pm 1.9$ & $5.8 \pm 4.0$ \\
\hline
\end{tabular}

The values indicate the CS levels at aroud 10:00 a.m. as mean \pm S.D. Adrenal demedullation and peripheral chemical-sympathectomy were carried out according to the methods described in the text. No significant differences were noted between the levels of 3 different groups.

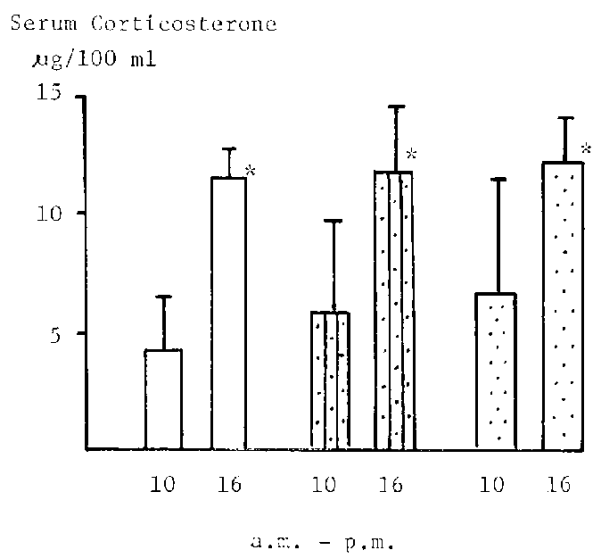

Fig. 3. Resting levels of serum corticosterone at 10 a.m. and 4 p.m. in intact, adrenal demedullated $\left(A D M_{x}\right)$, and peripheraliy chemicalsympathectomized ADMx rats. : 7 : Control intact rats, ADMx rats, $: D \cdot$ : Peripherally chemical-sympathectomized ADMx rats. * Significantly different from the levels at 10 a.m. time $(p<0.05)$. L : S.D.

much less than that of the control intact rats. An addition of peripheral chemicalsympathectomy with 6-hydroxydopamine, however, resulted in enhancement in increase of serum CS which was low in ADM $x$ rats (Fig. 4). Peripheral chemical-sympathectomy with guanethidine of $A D M_{x}$ rats also produced a higher increase in serum CS level than that of $\mathrm{ADM}_{x}$ rats under cold stress, such as was observed in peripherally chemical-sympathectomized with 6-hydroxydopamine ADM $x$ rats (Fig. 5).

Morphologic and histologic changes in spleen of chemically-sympathectomized rats: Spleens of $\mathrm{ADM}_{\mathrm{X}}$ rats examined 10 days after peripheral chemical-sympathectomy with 6 hydroxydopamine were deeply reddish near brown in contrast to the bright red color in the control intact rats. The shape was round and thickset, while the shape of the spleen from intact rats was long with a sharp edge and thin. The weight of the spleen of peripherally chemical-sympathectomized rats was significantly heavier than that of the control intact rats (Table 2). Light microscopic examination revealed that the white pulp of the spleen of peripherally chemicalsympathectomized rats was remarkably enlarged and surrounded by red pulp containing more red blood cells than in the case of the control intact rats (Fig. $6 \mathrm{a}, \mathrm{b}$ ).

\section{DISCUSSION}

The present study with $A D M_{X}$ rats indicated that the basal secretion of corticosteroids (CS) was not affected by inhibition of the function of the peripheral adrenergic nervous system by 6-hydroxydopamine. Diurnal variation of the serum CS level was not affected by peripheral chemical-sympathectomy, suggesting that hypothalamo- 
Table 2. Spleen weights of intact. adrenal demedullated (ADMx) and peripherally chemical-sympathectomized ADM $\mathrm{x}$ rats

\begin{tabular}{lcc}
\hline Rat & $N$ & $\begin{array}{c}\text { Spleen Weight }(g) \\
\text { (mean S.D.) }\end{array}$ \\
Intact & 36 & $0.58 \pm 0.36$ \\
ADM & 33 & $0.68 \pm 0.22$ \\
ADM $_{x}+$ Chemical-sympathectomized & 40 & $0.79 \pm 0.18^{*}$ \\
\hline
\end{tabular}

* Significantly different.from intact rats, $p<0.05$
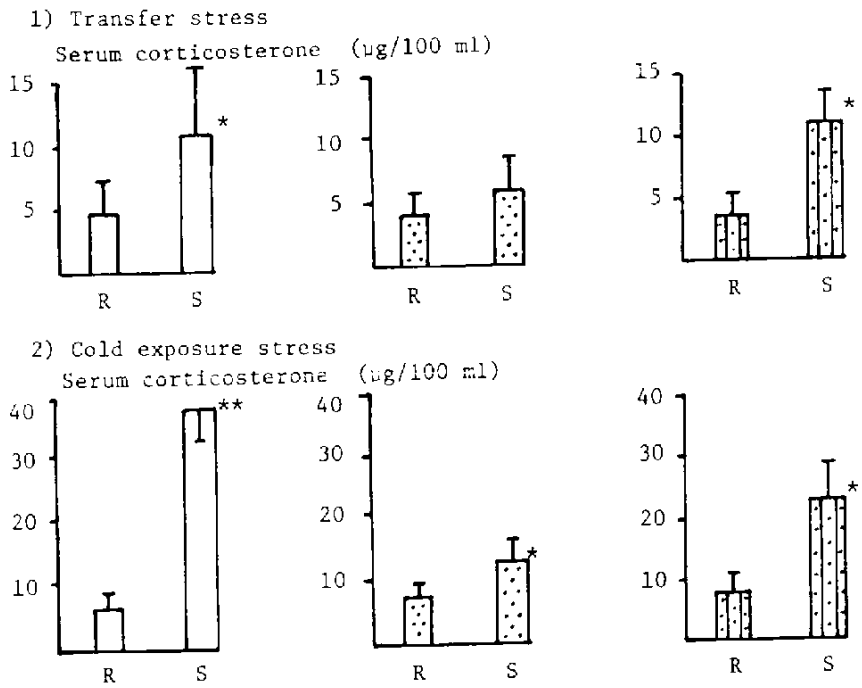

3) Forced swiming stress

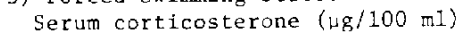

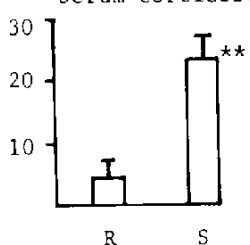

Control intact rats

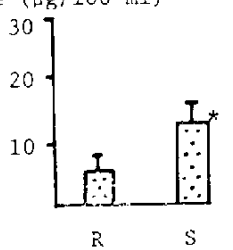

Adrenal demedullated $\left(\mathrm{ADM}_{\mathrm{X}}\right)$ rats

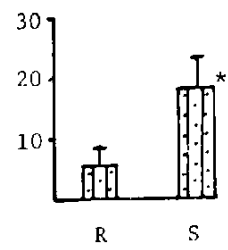

$A D M_{x}+$ peripherally sympathectomized rats

Fig. 4. Changes in the levels of serum corticosterone of rats produced by exposure to stress. L 1: Control intact rats, ::: Adronal demedullated rats (ADMx rats), :D: : Peripherally chemical-sympathectomized ADMx rats. R: Resting level, S: Level immediately after exposure to stress. * * : Significantly different from the resting level, ${ }^{*} p<0.05,{ }^{*} p<0.01$.

pituitary-adrenocortical function is not influenced by changes in the function of peripheral adrenergic nervous system in the resting condition. Under conditions of stress, however. CS secretion from the adrenal gland was remarkably affected by suppression of peripheral adrenergic functions. The significant increase in serum CS in stressed intact rats was significantly suppressed by adrenal demedullation. On the hand, the decrease of adrenocortical response in serum CS of $A D M_{x}$ rats tended to recover in 


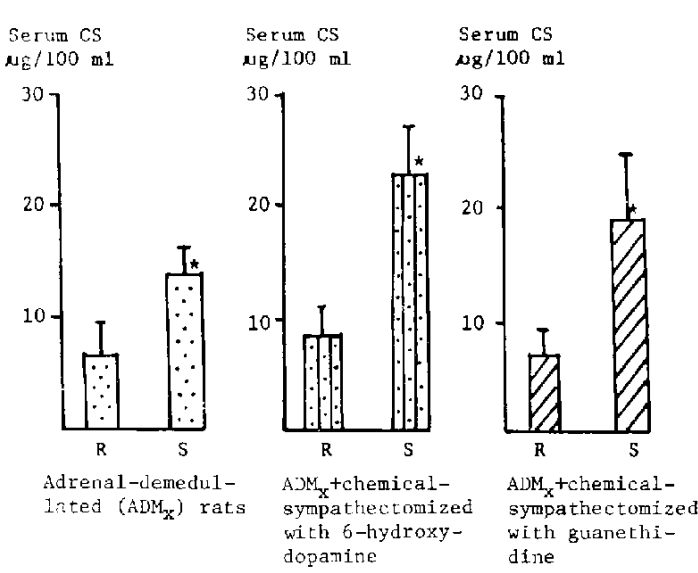

Fig. 5. Larger increases in serum corticosterone by exposure to cold stress in adrenal demedullated (A.DMx) rats sympathectomized periphcrally with 6-hydroxydopamine or guanethidine, as compared to $A D M x$ rats. Adrenal demedullated (ADMx) rats, [:-A]: $A D M_{X}+$ chemically sympathectomized rats with 6 hydroxydopamine. WIIL: ADMx+chemically sympathectomized rats with guanethidine. R: Resting level, S: Leve! after exposure to cold stress. *: Significantly different from $R$. $0<0.05$.

peripherally chemical-sympathectomized

ADM $M_{x}$ rats given stress.

The lowered response of the adrenal gland to stress in ADM $M_{x}$ rats may be explained by the abscence of adrenaline which will stimulate ACTH secretion from the anterior pituitary gland in rats. A lower but significant increase in the serum $C S$ of $A D M_{x}$ rats under stress may be due to stimulation of hypothalamo-pituitary-adrenocortical functions. Enhancement of adrenocortical response to stress by chemical-sympathectomy in ADM $_{x}$ rats, however, seems difficult to explain. In the peripherally chemical-sympathectomized $A D M_{x}$ rats, the response of adrenocortical tissue to the exogenous ACTH was to the same extent as seen in the intact rats, therefore the demedullated adrenal gland itself may not be responsible for the phenomenon described above. It may be assumed that noradrenaline from peripheral adrenergic

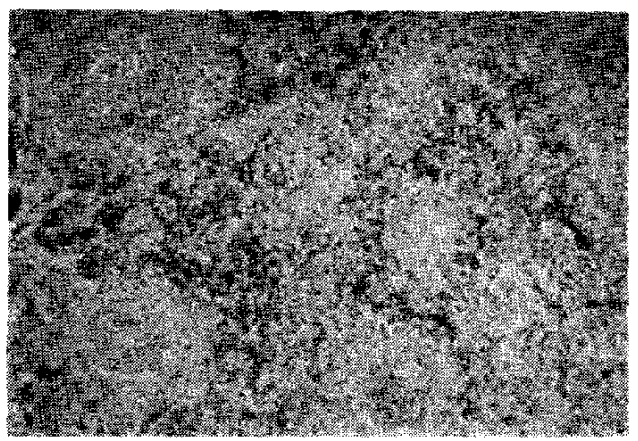

(a)

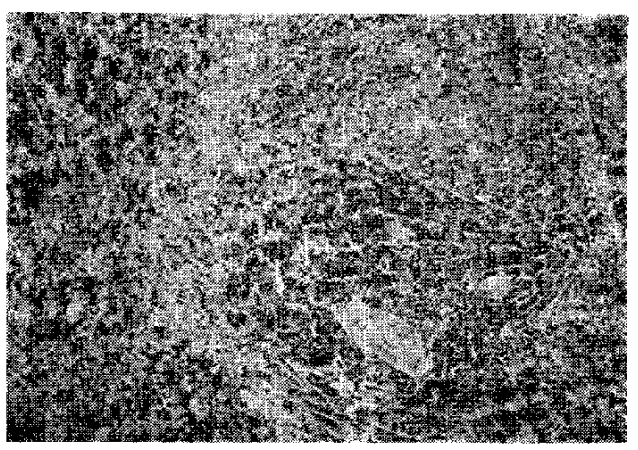

(b)

Fig. 6-a,b. Histology of the spleen of intact control rats (a) and periphorally chemical-sympathoctomized adrenal-demedullated rats (b). $H-E$ stain $\times 50$

neurons works as an inhibitory factor on the hypothalamo-pituitary-adrenal axis via afferent influences from peripheral organs or tissues that are stimulated by noradrenaline. Although Naumenko (2) reported that the peripherally acting adrenergic agent. naphtyzin, stimulated $\mathrm{ACTH}$ release from anterior pituitary gland in the guinea pig. it has been speculated that functional changes in the peripheral adrenergic structure would relate to the function of the central nervous system and both stimulatory and inhibitory effects on release of corticotropin-releasing factor from the hypothalamus would be produced through receptor mechanisms involved in the peripheral tissues (9). Atrial receptors may also be involved in control mechanisms related to ACTH secretion (10). 
Morphologic and histologic changes were observed in the spleen of peripherally chemical-sympathectomized ADM $x$ rats and such alterations were probably due to noradrenaline depletion in the peripheral adrenergic system following chemical-sympathectomy with 6-hydroxydopamine.

\section{REFERENCES}

1) Guillemin, R.: A re-valuation of acetylcholine, adrenaline. noradrenaline and histamine as possible mediators of pituitary adrenocorticotrophic activation by stress. Endocrinology 56, 248-255 (1955)

2) Naumenko, E.V.: Role of adrenergic and cholinergic structures in control of the pituitaryadrenal system. Ibid 80, 69-76 (1967)

3) Weiner, R.J. and Ganong, W.F.: Role of brain monoamines and histamine in regulation of anterior pituitary secretion. Physiol. Rev. 58, 905-976 (1978)

4) Angeletti, P.U.: Chemical sympathectomy in the newborn. Immunosympathectomy, Edited by Steiner. G. and Schonbaum. E., pp. 237250. Elsevier Publishing Co., Amsterdam-
London-New York (1972)

5) Johnson, E.M. Jr. and O'Brien, F.: Evaluation of the permanent sympathectomy produced by the administration of guanethidine to adult rats. J. Pharmacol. exp. Ther. 196, 53-61 (1976)

6) Anton, A.H. and Sayre, D.F.: A study of the factors affecting the aluminum oxide-trihydroxyindole procedure for the analysis of catecholamines. Ibid 138, 360-375 (1962)

7) Inaba, M., Kamata, K., Imai, S. and Nakao, T.: Studies on secretion mechanism of adrenal corticosterone: adrenal subcellular distribution of corticosterone and its changes on hypophysectomy and ACTH administration. J. Steroid Biochem. 3, 907-917 (1972)

8) Guillemin, R., Clayton, G.W., Liscomb, H.S. and Smith, J.D.: Fluorometric measurement of rat plasma and adrenal corticosterone concentration: a note on technical details. J. Lab. Clin. Med., 53, 830-832 (1959)

9) Van Loon, G.R.: Brain catecholamines and ACTH secretion. Frontier in Neuroendocrinology, Edited by Ganong, W.F. and Martini. L., p. 209. Oxford University Press, London (1973)

10) Baertschi, A.J., Ward, D.G. and Gann, D.S.: Role of atrial receptors in control of ACTH. Am. J. Physiol. 231, 692-699 (1976) 